\title{
Robotic-assisted laparoscopic myomectomy: the feasibility in single-site system
}

\author{
Su Hyeon Choi, Soyeon Hong, Miseon Kim, Hyo Sook Bae, Mi Kyoung Kim, Mi-La Kim, Yong Wook Jung, \\ Bo Seong Yun, Seok Ju Seong
}

Department of Obstetrics and Gynecology, CHA Gangnam Medical Center, CHA University School of Medicine, Seoul, Korea

\section{Objective}

To evaluate the feasibility of robotic single-site myomectomy (RSSM).

\section{Methods}

Medical records of 355 consecutive women who underwent robotic-assisted laparoscopic myomectomy were retrospectively reviewed. Clinical characteristics were compared between multi-site and single-site systems. After 1:1 propensity score matching for the total myoma number, largest myoma size, and total tumor weight (105 women in each group), surgical outcomes were also compared between the 2 systems.

\section{Results}

A total of $105(29.6 \%)$ and 250 (70.4\%) women underwent RSSM and robotic multi-site myomectomy (RMSM), respectively. RSSM was more commonly performed in women with lower body mass index $\left(21.6 \mathrm{vs} .22 .5 \mathrm{~kg} / \mathrm{m}^{2}\right.$, $P=0.014)$, without peritoneal adhesions $(7.6 \%$ vs. $24.8 \%, P<0.001)$, and less $(2.6$ vs. $4.6, P<0.001)$ and smaller $(6.3$ vs. $7.7 \mathrm{~cm}, P<0.001)$ myomas compared to RMSM. After propensity score matching, the largest myoma size $(P=0.143)$, total myoma number $(P=0.671)$, and tumor weight $(P=0.510)$ were not significantly different between the 2 groups. Although the docking time was significantly longer in the RSSM group ( $5.1 \mathrm{vs.} 3.8$ minutes, $P=0.005$ ), total operation time was similar between RSSM and RMSM groups ( 145.9 vs. 147.3 minutes, $P=0.856$ ). Additionally, hemoglobin decrement was lower in the RSSM group than in the RMSM group (1.4 vs. $1.8 \mathrm{~g} / \mathrm{dL}, P=0.009)$. No surgical complication was observed after RSSM, while 1 ileus and 2 febrile complications occurred in women that underwent RMSM $(0 \%$ vs. $2.9 \%, P=0.246)$.

\section{Conclusion}

Although RMSM is preferred for women with multiple large myomas in real clinical practice, RSSM seems to be a feasible surgical method for less complicated cases, and is associated with minimal surgical morbidity.

Keywords: Myomectomy; Robotic surgical procedures; Feasibility studies

\section{Introduction}

Myoma uteri is a common gynecologic disease that occurs in $50-60 \%$ of women in their reproductive age [1]. Myomectomy is one of the essential surgical therapeutic options for this disease. Laparo-endoscopic myomectomy has been shown to significantly improve surgical outcomes compared to laparotomy in terms of blood loss, postoperative complications, and recovery period $[2,3]$. Moreover, with the increasing demand of young women for reduced surgical scars, the demand for laparo-endoscopic single-site (LESS) myomectomy has also increased $[4,5]$. However, LESS surgery has not been famil-
Received: 2018.06.09. Revised: 2018.10.25. Accepted: 2018.10.26. Corresponding author: Miseon Kim

Department of Obstetrics and Gynecology, CHA Gangnam Medical Center, CHA University School of Medicine, 566

Nonhyeon-ro, Gangnam-gu, Seoul 06135, Korea

E-mail: miseonkim@chamc.co.kr

https://orcid.org/0000-0002-5118-9275

Articles published in Obstet Gynecol Sci are open-access, distributed under the terms of the Creative Commons Attribution Non-Commercial License (http://creativecommons. org/licenses/by-nc/3.0/) which permits unrestricted non-commercial use, distribution, and reproduction in any medium, provided the original work is properly cited.

Copyright (c) 2019 Korean Society of Obstetrics and Gynecology 


\section{Obstetrics \& Gynecology Science}

Su Hyeon Choi, et al. Robotic-assisted laparoscopic myomectomy

iar with the surgical armature in gynecology, as it requires manipulation of three articulating instruments through just one access port and has a lack of triangulation, instrument crowding, a need for special instruments, and poor ergonomics [6-9].

The da Vinci $^{\circledR}$ system (Intuitive Surgical, Inc., Sunnyvale, (A, USA) made overcoming technical difficulties associated with laparo-endoscopic myomectomy possible. The system provides a stable three-dimensional vision, instruments with a wrist function, tremor elimination, greater precision in dissection, easier knot-and-tying, and favorable ergonomics $[10,11]$. Recently, robotic single-site surgery has already been used in various gynecologic fields, including in myomectomy [10-13]. However, it also has some limitations, such as an unfamiliar docking process, unarticulated semirigid instruments, and lack of monopolar scissors. Therefore, myomectomy has preferably been performed with multi-site system rather than with single-site system until now, even in robotic surgery.

To confirm the feasibility of robotic single-site myomectomy (RSSM) for various myoma indications, we evaluated the clinical characteristics and surgical outcomes of consecutive women who underwent RSSM and robotic multi-site myomectomy (RMSM) since our institution had adopted the da Vinci $^{\circledR}$ Si system.

\section{Materials and methods}

\section{Patients}

A total of 355 women who underwent robot-assisted laparoscopic myomectomy between September 2015 and February 2018 were included. Medical records of all included women were retrospectively reviewed. Collected data included age, body mass index (BMI), marital status, parity, and previous abdominal surgeries. Patients also underwent preoperative evaluations including laboratory testing to check the hemoglobin level. The decision to operate was based on the mutual agreement between the patient and surgeon after the assessment and appropriate counseling upon the initial clinic visit.

\section{Surgical procedures}

The operation was performed by six gynecologic surgeons experienced in laparo-endoscopic surgery. All patients were placed in lithotomy position under general endotracheal anesthesia; then, a urethral Foley catheter was inserted and a uterine manipulator (CooperSurgical Inc., Trumbull, CT, USA) was placed.

\section{1) Robotic multi-sites myomectomy}

After creating a pneumoperitoneum using a Veress needle inserted at the umbilicus, four trocars were placed: a 12-mm trocar for the camera port was placed either at or above the umbilicus, two lateral trocars of $8 \mathrm{~mm}$ each were placed at the lower quadrant of the abdomen $2-3 \mathrm{~cm}$ below the umbilical level, and the fourth 5-mm assistant trocar was placed at mid-distance between the umbilicus and the left robotic arm. The fourth 5-mm trocar for the assist port was placed 4 $\mathrm{cm}$ vertically higher from the median point between the right lower quadrant port and the camera port. A surgical cart with 3 robotic arms was placed and vertically docked. The bedside assistant surgeon introduced the suction-irrigation instruments and suture materials through the assist port.

After inspecting the surgical field, using an aspiration needle through an assist port, a diluted solution of vasopressin with a $0.25 \mathrm{U} / \mathrm{mL}$ concentration was injected into the serosa and myometrium surrounding the myoma to achieve hemostasis. At beginning, a monopolar curved scissor was held in the right arm, and a fenestrated-bipolar forceps was held in the left arm. Myoma resection was performed with scissors in one robotic arm and a tenaculum in the other. Continuous suturing was performed with 1-0 V-Loc ${ }^{\mathrm{TM}}$ (Covidien, Dublin, Ireland) to repair the myometrium using a wristed needle holder in one robotic arm and a fenestrated bipolar forceps in the other. The suturing for defective uterine wall was individually performed depending on the location and size of the myoma and the presence of endometrium injury. The uterine wall in women with a future pregnancy plan was usually repaired by suturing of 2 or more layers.

Both robotic arms were undocked, and the 12-mm camera port was then replaced with an electric power morcellator to remove the resected myomas, and the camera was replaced with a smaller one (5 $\mathrm{mm}$ in diameter) introduced through the assist port. Morcellation was usually conducted without bag under a conventional laparoscopy, and then the pelvis and abdomen were irrigated. The fascia was sutured at the three port sites that were used for the robotic arms and camera, and the skin in all four port sites was sutured.

2) Robotic single-site myomectomy

A vertical $2.3-2.5 \mathrm{~cm}$ transumbilical skin incision was made, 


\section{Obstetrics \& Gynecology Science}

Vol. 62, No. 1, 2019

and the fascia layer was opened. The da Vinci ${ }^{\circledR}$ single-site $^{\circledR}$ surgical platform of silicon was inserted using long Kelly forceps and an Army-Navy retractor. The $30^{\circ} 8.5-\mathrm{mm}$ da Vinci stereo laparoscope connected to the robotic system camera was inserted to check the atraumatic placement of its primary port. Then, the camera was removed, and the robotic system was positioned centrally between the patient's legs and docked at the camera port. Two 5-mm curved cannulae were inserted into the docked robotic arms, and dedicated semirigid instruments were loaded under careful stereolaparoscopic guidance. Flexible robotic instruments, such as a monopolar hook and fenestrated bipolar forceps, were mounted through curved cannulas, and the robotic system provided a switching motion between the right- and lefthand orientations. To repair the uterine wall after myoma resection, continuous suturing was performed with 1-0 VLoc ${ }^{\mathrm{TM}}$ using a needle holder in one robotic arm and a fenestrated bipolar forceps in the other. The repair was similar to that performed in RSSM.

In RSSM, the extracted myomas were put into an Endopouch $^{\circledast}$ specimen retrieval bag (Ethicon, Johnson \& Johnson, New Brunswick, NJ, USA). The specimen in the Endopouch ${ }^{\circledR}$ was chopped by scalpel and removed from the peritoneal cavity through the umbilical incision site. Then, the single-site port was reinserted, and three reusable straight trocars were placed to assess the pelvic cavity and irrigate the peritoneal cavity. The fascia and subcutaneous layers were approximated with 1-0 Vicryl sutures (Ethicon).

Patients received appropriate parenteral fluid and antibiotic administration in the operation day. At first postoperative day, progressive dietary and surgical wound care were provided. Patients were usually discharged at postoperative day 3 in absence of any suspected complication. Outpatient follow-up was usually scheduled at 1 week after discharge.

\section{Data characteristics}

Data pertaining to intraoperative findings, such as peritoneal adhesion, concurrent procedure, total number of retrieved myomas, location and type of the largest myoma, and tumor weight in the retrieved myomas, were collected. Surgical outcomes, including port placement time, docking time, console time, morcellation time, incision repair time, total operation time, estimated blood loss, hemoglobin level decrement, transfusion, hospital stay duration, and postoperative complications, were also evaluated. Docking time was the time taken to position the robot and securely install the robotic arms at the port sites. Console time was the time spent by the surgeon at the robotic console to perform the operation. Total operation time was the time from the first skin incision to the last port site skin closure. Ileus was defined as diffuse abdominal discomfort with signs of trapped gas on plain abdomen $\mathrm{X}$-ray. Fever was defined as a persistent temperature $>37.3^{\circ} \mathrm{C}$ more than 3 days after surgery. Wound dehiscence was defined as the failure of a surgical wound to close properly.

\section{Statistical analysis}

Student's $t$-test was used for continuous variables, and $\chi^{2}$ test was used for categorical variables. Mann-Whitney $U$ test and Fisher's exact test were used for non-parametric statistics. To evaluate the surgical outcomes with minimized selection bias, 1:1 (nearest) propensity score matching was performed for the total myoma number, largest myoma size, and tumor weight between RSSM and RMSM groups. Analyses were conducted using SPSS version 24.0 (IBM Inc., Armonk, NY, USA), and $P$-values $<0.05$ were considered statistically significant.

\section{Results}

\section{Baseline characteristics and intraoperative findings} Among the total of 355 women with single or multiple myomas who needed surgical treatment, 105 (29.6\%) and 250 (70.4\%) women received RSSM and RMSM, respectively. There were 3 cases with multi-port conversion and 1 case with laparo-endoscopy conversion during surgery in RSSM group. All conversion to multi-port and laparo-endoscopy were related to technical difficulty. There was no open conversion case in both groups (Fig. 1).

Baseline characteristics of patients from RSSM and RMSM groups are presented in Table 1. The mean age at surgery was not different between the women from RSSM and RMSM groups ( $36.7 \pm 6.3$ vs. $37.6 \pm 5.4$ years, $P=0.145)$. Only the mean BMI $\left(22.5 \pm 3.2\right.$ vs. $\left.21.6 \pm 3.2 \mathrm{~kg} / \mathrm{m}^{2}, P=0.014\right)$ was higher in women that underwent RMSM, while the proportions of unmarried $(48.6 \%$ vs. $40.4 \%, P=0.156)$ and nulliparous $(73.3 \%$ vs. $79.6 \%, P=0.195)$ women were similar between the two groups. Moreover, the proportions of women who previously underwent other abdominal sur- 


\section{Obstetrics \& Gynecology Science}

Su Hyeon Choi, et al. Robotic-assisted laparoscopic myomectomy

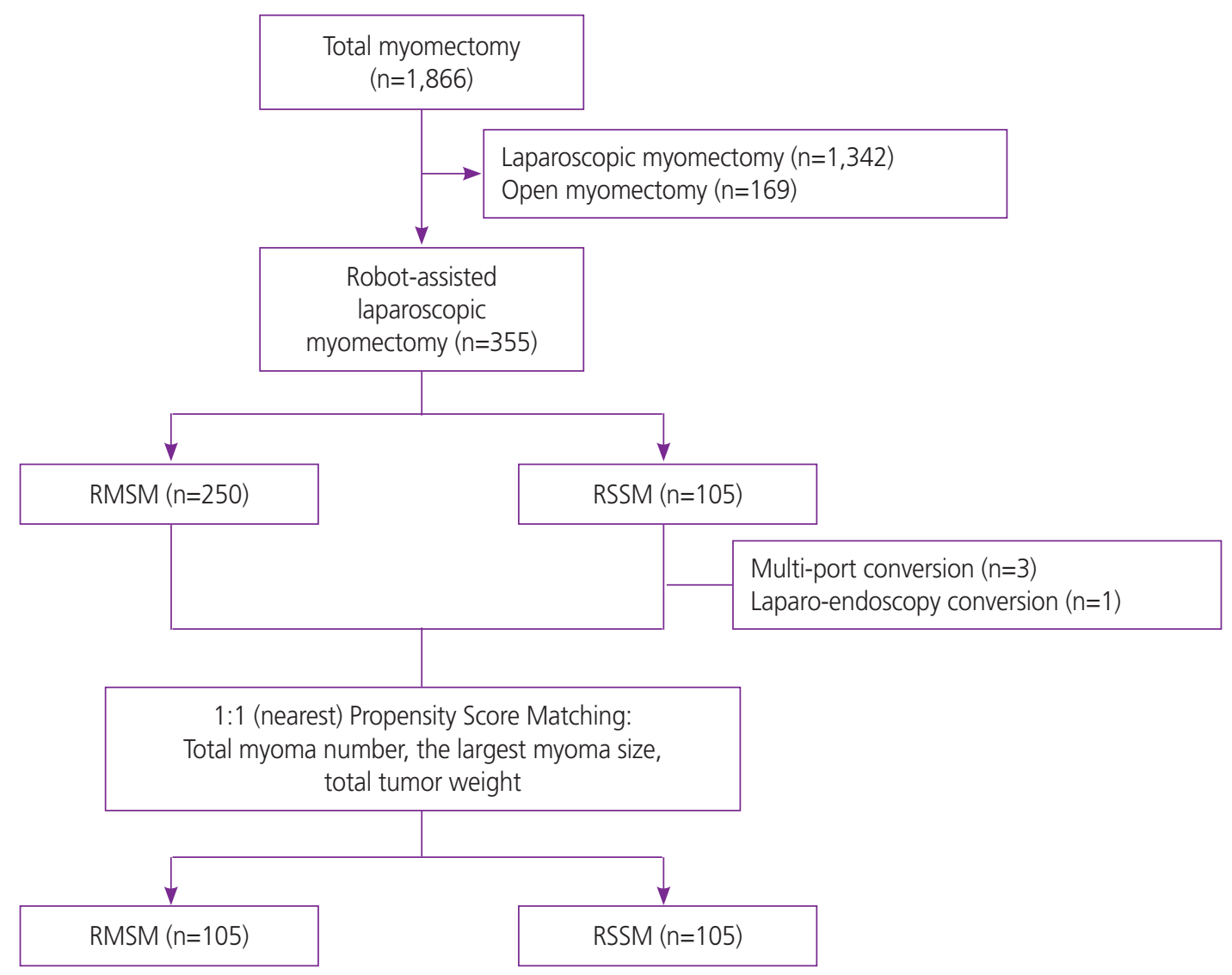

Fig. 1. Flow diagram of study population. RMSM, robotic multi-site myomectomy; RSSM, robotic single-site myomectomy.

geries were also similar between the groups $(18.1 \%$ vs. $14.0 \%, P=0.327)$. Peritoneal adhesion ( $24.8 \%$ vs. $7.6 \%$, $P<0.001$ ) was more frequently found in women from RMSM group than in those from RSSM group. The mean number of retrieved myomas was higher in women that underwent RMSM (4.6 \pm 4.1 vs. $2.6 \pm 2.3, P<0.001)$. In addition, the average dimensions of largest myomas were $6.3 \pm 1.7 \mathrm{~cm}$ and $7.7 \pm 2.5 \mathrm{~cm}$ in RSSM and RMSM groups, respectively $(P<0.001)$. The location $(P=0.481)$ and type $(P=0.836)$ of the largest myoma were not different between the two groups. The estimated weight of retrieved myomas was greater in RMSM group than in RSSM group $(250.8 \pm 208.1$ vs. $114.9 \pm 83.9 \mathrm{~g}, P<0.001)$. Concurrent ovarian surgery rate was not different between the groups $(11.4 \%$ vs. $10.0 \%$, $P=0.688$ ).

\section{Surgical outcomes and morbidity}

To compare the surgical outcomes with minimized selection bias, we performed the 1:1 (nearest) propensity score matching for total retrieved myoma number, largest myoma size, and total tumor weight. Table 2 shows the matched parameters between the RSSM and RMSM groups. After propensity matching, the total myoma number $(2.6 \pm 2.3$ vs. $2.7 \pm 2.2$, $P=0.671)$, the largest myoma size $(6.3 \pm 1.7$ vs. $6.6 \pm 2.0$ $\mathrm{cm}, P=0.143)$, and the total tumor weight $(114.9 \pm 83.9$ vs. $133.7 \pm 82.6 \mathrm{~g}, P=0.510$ ) were not significantly different between the 2 groups.

Table 3 shows the surgical outcomes of RSSM and RMSM after propensity score matching. Docking time was significantly longer in RSSM than in RMSM $(5.1 \pm 3.6$ vs. $3.8 \pm 2.9$ minutes, $P=0.005)$. However, the total operation time was similar between the 2 groups $(145.9 \pm 53.7$ vs. $147.3 \pm 16.1$ minutes, $P=0.856)$. Intraoperative blood loss $(210.1 \pm 1.1$ vs. $213.9 \pm 1.1 \mathrm{~mL}, P=0.869)$ was not different between the 2 groups; however, hemoglobin level decrement $(1.4 \pm 0.1$ vs. $1.8 \pm 1.1 \mathrm{~g} / \mathrm{dL}, P=0.009$ ) was lower in women who underwent RSSM than in those who underwent RMSM. Although not statistically significant, blood transfusion rate was higher in women from RMSM group ( $4.8 \%$ vs. $0 \%, P=0.212$ ). On the contrary, the duration of hospital stay was longer after 


\title{
Obstetrics \& Gynecology Science
}

\author{
Vol. 62, No. 1, 2019
}

Table 1. Baseline characteristics in women who received robotic single-site and multi-site myomectomy

\begin{tabular}{|c|c|c|c|}
\hline Characteristics & RSSM (n=105) & RMSM (n=250) & $P$-value \\
\hline Age (yr) & $36.7 \pm 6.3$ & $37.6 \pm 5.4$ & 0.145 \\
\hline $\mathrm{BMI}\left(\mathrm{kg} / \mathrm{m}^{2}\right)$ & $21.6 \pm 3.2$ & $22.5 \pm 3.2$ & 0.014 \\
\hline Married & & & 0.156 \\
\hline No & $51(48.6)$ & $101(40.4)$ & \\
\hline Yes & $54(51.4)$ & $149(59.6)$ & \\
\hline Nullipara & & & 0.195 \\
\hline No & $28(26.7)$ & $51(20.4)$ & \\
\hline Yes & $77(73.3)$ & $199(79.6)$ & \\
\hline Previous abdominal surgery & & & 0.327 \\
\hline No & $86(81.9)$ & $215(86.0)$ & \\
\hline Yes & $19(18.1)$ & $35(14.0)$ & \\
\hline Peritoneal adhesion & & & $<0.001$ \\
\hline No & $97(92.4)$ & $188(75.2)$ & \\
\hline Yes & $8(7.6)$ & $62(24.8)$ & \\
\hline Total myoma (No.) & $2.6 \pm 2.3$ & $4.6 \pm 4.1$ & $<0.001$ \\
\hline \multicolumn{4}{|l|}{ The largest myoma } \\
\hline Size $(\mathrm{cm})$ & $6.3 \pm 1.7$ & $7.7 \pm 2.5$ & $<0.001$ \\
\hline Location & & & 0.481 \\
\hline Anterior & $44(41.9)$ & $105(42.0)$ & \\
\hline Anterior fundus & $2(1.9)$ & $4(1.6)$ & \\
\hline Fundus & $14(13.3)$ & $37(14.8)$ & \\
\hline Posterior fundus & $2(1.9)$ & $7(2.8)$ & \\
\hline Posterior & $43(41.0)$ & $97(38.8)$ & \\
\hline Type & & & 0.836 \\
\hline Submucosal & $4(3.8)$ & $5(2.0)$ & \\
\hline Deep intramural & $53(50.5)$ & $114(45.6)$ & \\
\hline Intramural & $24(22.9)$ & $70(28.0)$ & \\
\hline Subserosal & $17(16.2)$ & $52(20.8)$ & \\
\hline Pedunculated subserosal & $2(1.9)$ & $2(0.8)$ & \\
\hline Intraligamentary & $5(4.8)$ & $7(2.8)$ & \\
\hline Tumor weight (g) & $114.9 \pm 83.9$ & $250.8 \pm 208.1$ & $<0.001$ \\
\hline Concurrent ovarian surgery & & & 0.688 \\
\hline No & $93(88.6)$ & $225(90.0)$ & \\
\hline Yes & $12(11.4)$ & $25(10.0)$ & \\
\hline Laparoscopy conversion & & & 0.296 \\
\hline No & $104(99.0)$ & $250(100.0)$ & \\
\hline Yes & $1(1.0)$ & 0 & \\
\hline Multi-site conversion & & & - \\
\hline No & $102(97.1)$ & - & \\
\hline Yes & $3(2.9)$ & - & \\
\hline Open conversion & & & - \\
\hline No & $105(100.0)$ & $250(100.0)$ & \\
\hline Yes & 0 & 0 & \\
\hline
\end{tabular}

Values are presented as number (\%), median (range) or mean \pm standard deviations.

RSSM, robotic single-site myomectomy; RMSM, robotic multi-site myomectomy; BMI, body mass index. 


\section{Obstetrics \& Gynecology Science}

Su Hyeon Choi, et al. Robotic-assisted laparoscopic myomectomy

Table 2. Baseline characteristics in the analyzed population after $1: 1$ propensity score matching

\begin{tabular}{|c|c|c|c|}
\hline Characteristics & RSSM (n=105) & RMSM (n=105) & $P$-value \\
\hline Age (yr) & $36.7 \pm 6.3$ & $37.2 \pm 5.6$ & 0.533 \\
\hline $\operatorname{BMI}\left(\mathrm{kg} / \mathrm{m}^{2}\right)$ & $21.6 \pm 3.2$ & $22.0 \pm 2.8$ & 0.242 \\
\hline Married & & & 0.007 \\
\hline No & $51(48.6)$ & $32(30.5)$ & \\
\hline Yes & $54(51.4)$ & $73(69.5)$ & \\
\hline Nullipara & & & 0.522 \\
\hline No & $28(26.7)$ & $24(22.9)$ & \\
\hline Yes & $77(73.3)$ & $81(77.1)$ & \\
\hline Previous abdominal surgery & & & 0.714 \\
\hline No & $86(81.9)$ & $88(83.8)$ & \\
\hline Yes & $19(18.1)$ & $17(16.2)$ & \\
\hline Peritoneal adhesion & & & 0.001 \\
\hline No & $97(92.4)$ & $79(75.2)$ & \\
\hline Yes & $8(7.6)$ & $26(24.8)$ & \\
\hline Total myoma (No.) & $2.6 \pm 2.3$ & $2.7 \pm 2.2$ & 0.671 \\
\hline \multicolumn{4}{|l|}{ The largest myoma } \\
\hline Size $(\mathrm{cm})$ & $6.3 \pm 1.7$ & $6.6 \pm 2.0$ & 0.143 \\
\hline Location & & & 0.888 \\
\hline Anterior & $44(41.9)$ & $47(44.8)$ & \\
\hline Anterior fundus & $2(1.9)$ & $2(1.9)$ & \\
\hline Fundus & $14(13.3)$ & $10(7.5)$ & \\
\hline Posterior fundus & $2(1.9)$ & $3(2.9)$ & \\
\hline Posterior & $43(41.0)$ & $43(41.0)$ & \\
\hline Type & & & 0.699 \\
\hline Submucosal & $4(3.8)$ & $4(3.8)$ & \\
\hline Deep intramural & $53(50.5)$ & $55(52.4)$ & \\
\hline Intramural & $24(22.9)$ & $25(23.8)$ & \\
\hline Subserosal & $17(16.2)$ & $19(18.1)$ & \\
\hline Pedunculated subserosal & $2(1.9)$ & $1(1.0)$ & \\
\hline Intraligamentary & $5(4.8)$ & $1(1.0)$ & \\
\hline Tumor weight (g) & $114.9 \pm 83.9$ & $133.7 \pm 82.6$ & 0.510 \\
\hline Concurrent ovarian surgery & & & 0.347 \\
\hline No & $93(88.6)$ & $97(92.4)$ & \\
\hline Yes & $12(11.4)$ & $8(7.6)$ & \\
\hline
\end{tabular}

Values are presented as number (\%), median (range) or mean \pm standard deviations.

RSSM, robotic single-site myomectomy; RMSM, robotic multi-sites myomectomy; BMI, body mass index.

RSSM than after RMSM ( $4.7 \pm 1.0$ vs. $4.4 \pm 1.3$ days, $P<0.001)$. No surgical complication was observed in RSSM in this study, while one ileus and 2 febrile complications in women occurred after RMSM ( $0 \%$ vs. $2.9 \%, P=0.246)$.

\section{Discussion}

During the study period, we conducted 355 consecutive robotic myomectomies including 105 (29.6\%) RSSMs and 250 (70.4\%) RMSMs. Among the women with RSSM, conversion 


\title{
Obstetrics \& Gynecology Science
}

\author{
Vol. 62, No. 1, 2019
}

Table 3. Surgical outcomes and morbidity in the analyzed population after 1:1 propensity score matching

\begin{tabular}{|c|c|c|c|}
\hline Characteristics & RSSM (n=105) & RMSM (n=105) & $P$-value \\
\hline \multicolumn{4}{|l|}{ Operation-related time } \\
\hline Port placement time (min) & $8.8 \pm 5.8$ & $8.1 \pm 5.0$ & 0.342 \\
\hline Docking time (min) & $5.1 \pm 3.6$ & $3.8 \pm 2.9$ & 0.005 \\
\hline Console time (min) & $91.5 \pm 42.6$ & $85.5 \pm 45.0$ & 0.328 \\
\hline Morcellation plus skin incision repair time (min) & $41.3 \pm 23.3$ & $47.4 \pm 16.1$ & 0.071 \\
\hline Total operation time (min) & $145.9 \pm 53.7$ & $147.3 \pm 16.1$ & 0.856 \\
\hline Estimated blood loss (mL) & $210.1 \pm 1.1$ & $213.9 \pm 1.1$ & 0.869 \\
\hline Hemoglobin decrement ( $\mathrm{g} / \mathrm{dL})$ & $1.4 \pm 0.1$ & $1.8 \pm 1.1$ & 0.009 \\
\hline Transfusion & & & 0.212 \\
\hline No & $104(99.0)$ & $100(95.2)$ & \\
\hline Yes & $1(1.0)$ & $5(4.8)$ & \\
\hline Hospital stay (day) & $4.7 \pm 1.0$ & $4.4 \pm 1.3$ & 0.023 \\
\hline Complications & & & 0.246 \\
\hline None & $105(100.0)$ & $102(97.1)$ & \\
\hline Reoperation within 1 wk & 0 & 0 & \\
\hline lleus & 0 & $1(1.0)$ & \\
\hline Fever $>3$ day & 0 & $2(1.9)$ & \\
\hline Wound dehiscence & 0 & 0 & \\
\hline
\end{tabular}

Values are presented as number (\%), median (range) or mean \pm standard deviations.

RSSM, robotic single-site myomectomy; RMSM, robotic multi-sites myomectomy.

to laparo-endoscopic surgery was necessary in one case due to severe pelvic adhesion. In addition, change to multi-site system during surgery was necessary in 3 cases due to surgeons' technical difficulty. After surgery, no operation-related complication was detected in women who underwent RSSM in this study. This complication rate is consistent with those of previous studies [14-16].

Advincula et al. [17] first described RMSM in 2004. In this case series of 35 patients, the mean operation time and the estimated blood loss were $230.8 \pm 83$ minutes and $169 \pm 198.7$ $\mathrm{mL}$, respectively. The conversion rate to laparotomy was $3 / 35$ (8.6\%). Subsequently, a meta-analysis clearly showed the lack of significant differences in terms of estimated blood loss, operation time, postoperative complications, and conversion rate between RMSM and LEMS myomectomy [18]. However, no clinical advantage of RMSM over LEMS myomectomy could be demonstrated. The authors also suggested that the comparison between RMSM and LEMS myomectomy is difficult due to heterogeneity of the disease, and that a robotic approach may be preferred in more complicated cases. Long-term outcomes, such as pain-relief, recurrence rate, and fertility need to be further clarified. Pitter et al. [19] reported pregnancy outcome in 107 women who conceived following RMSM: a total of 92/127 deliveries/pregnancies with vaginal delivery, less than $5 \%$ complications, and one uterine rupture. There is no report regarding pregnancy outcomes after RSSM until now. Because the single-site system may be vulnerable to knot-and-tying technique, especially in deep intramural, multiple, or large myoma, surgeons should inform women scheduled to RSSM about the potential disadvantages in respect to pregnancy outcomes.

Many surgeons, even experienced, admitted that the greatest challenge for LESS surgery is suturing. Robotic single-site system has been considered to be helpful for suture-intensive procedures such as myomectomy $[12,20]$. Gargiulo et al. [14] and Lewis et al. [15] first reported the results of RSSM using the da Vinci $^{\circledR}$ system in 2015; then, they consecutively published a step-by-step tutorial on their technique and the outcomes of their first series of 10 women, and found RSSM to be a feasible and reproducible surgery. Choi et al. [16] reported a series of 61 women that underwent RSSM and suggested that the procedure was feasible and safe even in a 


\section{Obstetrics \& Gynecology Science}

Su Hyeon Choi, et al. Robotic-assisted laparoscopic myomectomy

large, multiple, or intramural myomas. No operation-related complications occurred, and no cases of added ports or conversion to laparotomy were reported. Although reports containing institutional tutorials or small-sized initial experiences are increasing, to the best of our knowledge, no studies comparing RSSM and RMSM have been published yet.

As a result of its retrospective nature, this study has some limitations. First, even though this was a large-scale population study, complete elimination of the surgeons' effect was not possible. All surgeons in this study were already experts in laparoscopic surgery with considerable experience; however, the total number for cases for each surgeon slightly varied. Second, the selection bias for surgical methods could affect the surgical outcomes. Because of the surgeons' tendency to choose "less complicated" surgical cases for RSSM, the surgical outcomes of RMSM seem to be much inferior to those of RSSM in this study.

Many surgeons still prefer RMSM in women with multiple large myomas. However, our results showed that RSSM also seems to be a feasible surgical method for women with smaller and less complicated myomas, and that this approach is associated with minimal surgical morbidity. Further studies are required to determine whether a robotic platform provides beneficial effects on fertility outcomes and which patient can be a proper candidate for robotic surgery. Technical stability in single-site system is a persisting problem that we must solve.

\section{Conflict of interest}

No potential conflict of interest relevant to this article was reported.

\section{Ethical approval}

This study was approved by the Institutional Review Board (GCl-18-24) at CHA Gangnam Medical Center and performed in accordance with the principles of the Declaration of Helsinki. Written informed consents were obtained.

\section{References}

1. Baird DD, Dunson DB, Hill MC, Cousins D, Schectman
JM. High cumulative incidence of uterine leiomyoma in black and white women: ultrasound evidence. Am J Obstet Gynecol 2003;188:100-7.

2. Mais V, Ajossa S, Guerriero S, Mascia M, Solla E, Melis GB. Laparoscopic versus abdominal myomectomy: a prospective, randomized trial to evaluate benefits in early outcome. Am J Obstet Gynecol 1996;174:654-8.

3. Seracchioli R, Rossi S, Govoni F, Rossi E, Venturoli S, Bulletti $C$, et al. Fertility and obstetric outcome after laparoscopic myomectomy of large myomata: a randomized comparison with abdominal myomectomy. Hum Reprod 2000;15:2663-8.

4. Borgfeldt C, Andolf E. Transvaginal ultrasonographic findings in the uterus and the endometrium: low prevalence of leiomyoma in a random sample of women age 25-40 years. Acta Obstet Gynecol Scand 2000;79:202-7.

5. Marsh EE, Ekpo GE, Cardozo ER, Brocks M, Dune T, Cohen LS. Racial differences in fibroid prevalence and ultrasound findings in asymptomatic young women (18-30 years old): a pilot study. Fertil Steril 2013;99:1951-7.

6. Lee HJ, Kim JY, Kim SK, Lee JR, Suh CS, Kim SH. Learning curve analysis and surgical outcomes of single-port laparoscopic myomectomy. J Minim Invasive Gynecol 2015;22:607-11.

7. Murji A, Patel VI, Leyland N, Choi M. Single-incision laparoscopy in gynecologic surgery: a systematic review and meta-analysis. Obstet Gynecol 2013;121:819-28.

8. Rao PP, Rao PP, Bhagwat S. Single-incision laparoscopic surgery - current status and controversies. J Minim Access Surg 2011;7:6-16.

9. Weibl P, Klingler HC, Klatte T, Remzi M. Current limitations and perspectives in single port surgery: pros and cons laparo-endoscopic single-site surgery (LESS) for renal surgery. Diagn Ther Endosc 2010;2010:759431.

10. Vizza E, Corrado G, Mancini E, Baiocco E, Patrizi L, Fabrizi $L$, et al. Robotic single-site hysterectomy in low risk endometrial cancer: a pilot study. Ann Surg Oncol 2013;20:2759-64.

11. Escobar PF, Fader AN, Paraiso MF, Kaouk JH, Falcone T. Robotic-assisted laparoendoscopic single-site surgery in gynecology: initial report and technique. J Minim Invasive Gynecol 2009;16:589-91.

12. Scheib SA, Fader AN. Gynecologic robotic laparoendoscopic single-site surgery: prospective analysis of feasibility, safety, and technique. Am J Obstet Gynecol 


\section{Obstetrics \& Gynecology Science}

Vol. 62, No. 1, 2019

2015;212:179.e1-8.

13. Cela V, Freschi L, Simi G, Ruggiero M, Tana R, Pluchino N. Robotic single-site hysterectomy: feasibility, learning curve and surgical outcome. Surg Endosc 2013;27:2638-43.

14. Gargiulo AR, Lewis El, Kaser DJ, Srouji SS. Robotic single-site myomectomy: a step-by-step tutorial. Fertil Steril 2015;104:e13.

15. Lewis El, Srouji SS, Gargiulo AR. Robotic single-site myomectomy: initial report and technique. Fertil Steril 2015;103:1370-1377.e1.

16. Choi EJ, Rho AM, Lee SR, Jeong K, Moon HS. Robotic single-site myomectomy: clinical analysis of 61 consecutive cases. J Minim Invasive Gynecol 2017;24:632-9.

17. Advincula AP, Song A, Burke W, Reynolds RK. Prelimi- nary experience with robot-assisted laparoscopic myomectomy. J Am Assoc Gynecol Laparosc 2004;11:511-8.

18. Pundir J, Pundir V, Walavalkar R, Omanwa K, Lancaster G, Kayani S. Robotic-assisted laparoscopic vs abdominal and laparoscopic myomectomy: systematic review and metaanalysis. J Minim Invasive Gynecol 2013;20:335-45.

19. Pitter MC, Srouji SS, Gargiulo AR, Kardos L, SeshadriKreaden $U$, Hubert $H B$, et al. Fertility and symptom relief following robot-assisted laparoscopic myomectomy. Obstet Gynecol Int 2015;2015:967568.

20. Eisenberg D, Vidovszky TJ, Lau J, Guiroy B, Rivas H. Comparison of robotic and laparoendoscopic single-site surgery systems in a suturing and knot tying task. Surg Endosc 2013;27:3182-6. 